\title{
COMPARATIVE ANALYSIS OF MULTILEVEL INVERTER TOPOLOGIES FOR INDUCTION MOTOR DRIVE APPLICATIONS
}

\author{
V.S. Prasadarao $K^{1}$, Gandham Tabita ${ }^{2}$ \\ ${ }^{1}$ Research Engineer, Naresh Engineering Coaching (NEC) Institute, Vijayawada, India \\ ${ }^{2} P G$ Scholar, Department of Electrical and Electronics Engineering, Gudlavalleru Engineering College, \\ Gudlavalleru, India
}

\begin{abstract}
Induction motors are widely used in industries, because they are rugged, reliable and economical and hence they are called as work horse power of industry. Induction motor drive requires suitable converters to get the required speed and torque without or negligible ripples. Multilevel inverters can do this job. But the conventional MLIs such as Diode Clamped MLIs requires extra diodes in conjunction with the active switches, Flying capacitor MLIs requires extra Capacitors and control also difficult if the levels increases and the Cascaded H-bridge MLIs requires separate dc sources which limits its use. This paper proposes a new type of multi level Inverter which converts the dc into ac using less number of switches when compared to conventional multilevel Inverters. The proposed Inverter uses only seven switches to get 13-level output voltage compared conventional cascaded H-bridge uses twelve switches. The comparison between the conventional MLIs and proposed inverter is presented in this paper. Finally the induction motor using proposed inverter with thirteen level is simulated using Matlab/Simulink environment and the corresponding results are presented in this paper.
\end{abstract}

Keywords- Grid interconnection, PV system, MLI, Renewable energy sources (RES).

\section{INTRODUCTION}

The AC induction motor is a rotating electric machine designed to operate a three-phase source of alternating voltage. The AC induction motor (ACIM) is the most popular motor used in consumer and industrial applications, and represented the "muscle" behind the industrial revolution. The induction motor is always rotating at synchronous speed; hence to get the speed control we need control the both voltage and frequency. Because voltage control of an ACIM means controlling the stator voltage by rheostat. But it gives more losses and less efficiency. Frequency control of ACIM results in saturation of core. Hence to get the speed control of induction motor, we need vary both voltage and current. This technique is called as constant V/F [1] method. By choosing the suitable inverter we can vary both voltage and frequency of the induction motor to get the required speed control. Normally the conventional H-bridge inverter produces a square output, which contains infinite number of odd harmonics and dv/dt stress is also high. Normal PWM inverter [2] can reduces the THD, but switching losses are high and also this inverter is restricted to low power applications. The importance of multilevel inverters [MLI] has been increased since last few decades [3], [4]. These new types of inverters are suitable for high voltage and high power application due to their ability to synthesize waveforms with better harmonic spectrum and with less THD. Generally MLIs are classified into three types: they are 1.Diode Clamped MLIs 2. Flying capacitor MLIs 3. Cascaded H-bridge MLIs. Diode clamped MLIs require large number of clamping diodes [5] as the level increases. In flying capacitor MLIs, Switching utilization and efficiency $[6,7]$ are poor and also it requires large number of capacitors as the level increases and cost is also high. Cascaded H-bridge MLIs are mostly preferred [8] for high power applications as the regulation of the DC bus is simple. But it requires separate dc sources and also the complexity of the structure is increases as the level predominantly increase. In order to address the above concerns, this paper proposes a new type of multilevel inverter which requires less number of DC sources and switches compared to Cascaded H-bridge MLIs.

\section{INDUCTION MOTOR DRIVE}

Generally a Drive is nothing but systems employed for motion control. Drives are classified into two types based on the nature of supply, they are DC drives and AC drives. The task of a variable speed electrical drive is to convert the electrical power supplied by the mains into mechanical power with a minimum loss. To achieve an optimum technological process, the drive must be variable in speed. Induction motor drive gain most importance in industries due to their rugged construction and reliability. The block diagram of the induction motor drive system is shown in figure 1 . 


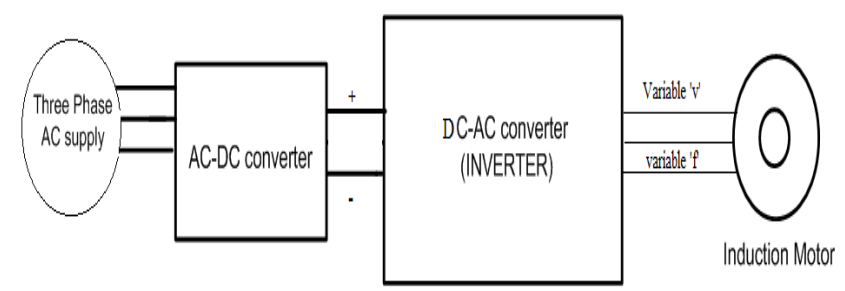

Fig 1 Induction motor drive system

The frequency of the fundamental AC voltage will determine the speed of IM. To vary the speed of IM, the inverter fundamental frequency need to be changed. The inverter output frequency must be kept close to the required motor speed.

The torque- speed characteristics of an induction motor is given by the formula:

$$
\mathrm{T}_{\mathrm{e}}=\frac{3}{\omega_{\mathrm{s}}} \frac{\mathrm{V}_{\mathrm{s}}^{2}}{\left(\mathrm{R}_{\mathrm{s}}+\frac{\mathrm{R}_{\mathrm{r}}^{\prime}}{\mathrm{s}}\right)^{2}+\left(\mathrm{X}_{\mathrm{ls}}+\mathrm{X}_{\mathrm{lr}}{ }^{\prime}\right)} \frac{\mathrm{R}_{\mathrm{r}}^{\prime}}{\mathrm{s}}
$$

The torque may be plotted as a function of 's' and is called the torque-slip (or torque-speed, since slip indicates speed) characteristic - a very important characteristic of the induction machine. The torque- speed characteristics of induction motor is shown in figure2.

Fig2: The torque- speed characteristics of induction motor

\section{PROPOSED TECHNOLOGY}

The general structure of proposed new multilevel inverter is shown in the figure 3 . It consists of a one H-bridge inverter and ' $N$ ' number of cascaded cells, which are having a dc rating of Vdc. The number of levels can be given by the formula:

$$
\text { Number of Levels }=[n(n+1)+1]
$$

Where $n=$ Number of cells excluding the H-bridge. For generating $+\mathrm{Vdc}$ we need turned on switches $\mathrm{S} 1$ and $\mathrm{S} 2$, for Vdc, switches S3 and S4 has to be turned on, and for zero voltage either switches $\mathrm{S} 1$ and $\mathrm{S} 3$ or switches $\mathrm{S} 2$ and $\mathrm{S} 4$ has to be turned on.

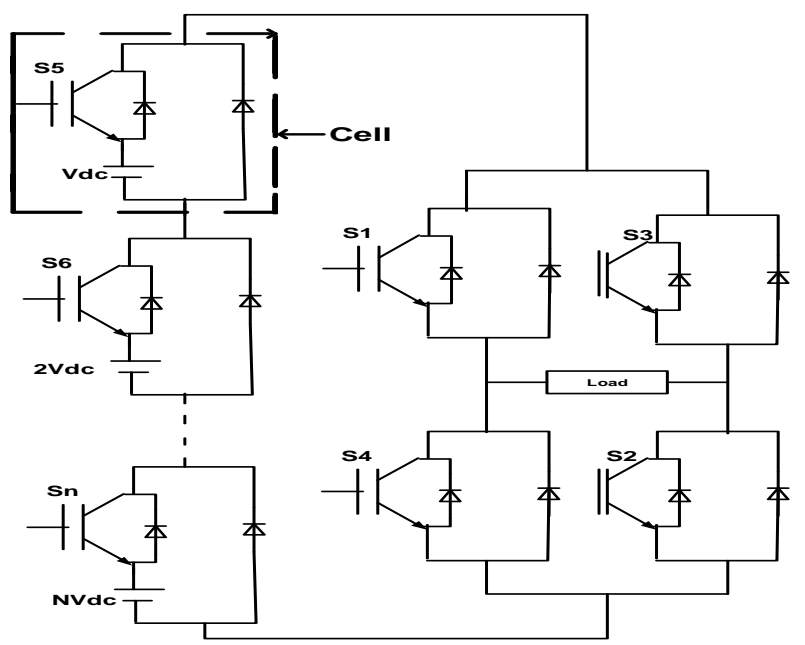

Fig3: General structure of proposed new multilevel inverter

\subsection{Thirteen Level Proposed Multilevel Inverter}

\section{(Symmetrical Configuration)}

Circuit diagram of proposed thirteen level multilevel inverter in symmetrical configuration is shown in figure 4 . The thirteen level proposed inverter in symmetrical configuration uses ten switches compared to cascaded H-bridge inverter in symmetrical configuration which uses twenty four switches and six separate dc sources. . But in proposed inverter, the requirement of separate dc sources is only six and hence the switching losses are also low. Using proper switching sequence proposed circuit generates thirteen levels in output voltage.

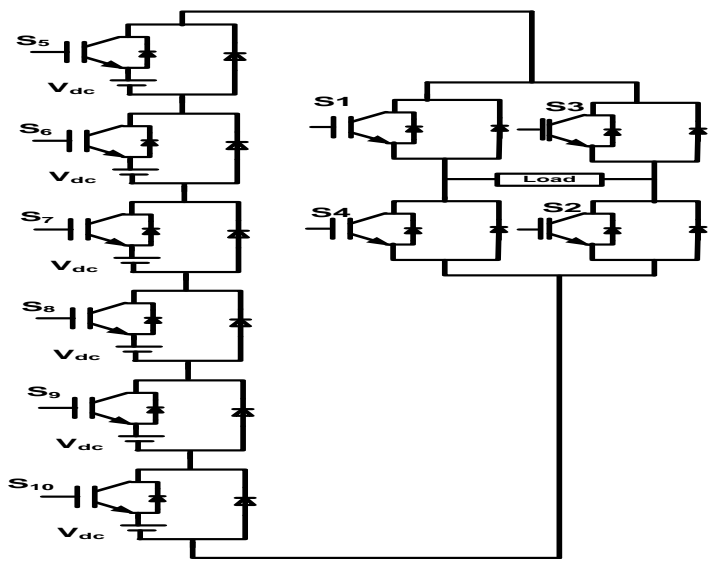

Fig4. Circuit diagram of thirteen level proposed inverter (symmetrical configuration) 
Table 1 shows the switching sequence used for creating thirteen levels for the output voltage in symmetrical configuration.

Table 1: Switching Sequence for proposed thirteen level Inverter (symmetrical configuration)

\begin{tabular}{|c|c|c|c|c|c|c|c|c|c|c|}
\hline sw1 & sw2 & sw3 & sw4 & sw5 & sw6 & sw7 & sw8 & sw9 & sw10 & Load Voltage \\
\hline ON & ON & OFF & OFF & ON & OFF & OFF & OFF & OFF & OFF & Vdc \\
\hline ON & ON & OFF & OFF & ON & ON & OFF & OFF & OFF & OFF & $2 \mathrm{Vdc}$ \\
\hline ON & ON & OFF & OFF & ON & ON & ON & OFF & OFF & OFF & $3 \mathrm{Vdc}$ \\
\hline ON & ON & OFF & OFF & ON & ON & ON & ON & OFF & OFF & $4 \mathrm{Vdc}$ \\
\hline ON & ON & OFF & OFF & ON & ON & ON & ON & ON & OFF & $5 \mathrm{Vdc}$ \\
\hline ON & ON & OFF & OFF & ON & ON & ON & ON & ON & ON & $6 \mathrm{Vdc}$ \\
\hline OFF & ON & OFF & ON & OFF & OFF & OFF & OFF & OFF & OFF & 0 \\
\hline OFF & OFF & ON & ON & ON & OFF & OFF & OFF & OFF & OFF & $-\mathrm{Vdc}$ \\
\hline OFF & OFF & ON & ON & ON & ON & OFF & OFF & OFF & OFF & $-2 \mathrm{Vdc}$ \\
\hline OFF & OFF & ON & ON & ON & ON & ON & OFF & OFF & OFF & $-3 \mathrm{Vdc}$ \\
\hline OFF & OFF & ON & ON & ON & ON & ON & ON & OFF & OFF & $-4 \mathrm{Vdc}$ \\
\hline OFF & OFF & ON & ON & ON & ON & ON & ON & ON & OFF & $-5 \mathrm{Vdc}$ \\
\hline OFF & OFF & ON & ON & ON & ON & ON & ON & ON & ON & $-6 \mathrm{Vdc}$ \\
\hline
\end{tabular}

\subsection{Thirteen Level Proposed Multilevel Inverter:}

\section{(Asymmetrical Configuration)}

The thirteen level proposed inverter symmetrical configuration uses only seven switches compared to cascaded H-bridge inverter which uses twenty four switches and six separate dc sources. But in proposed inverter, the requirement of separate dc sources is only three and the switching losses are also low. Using proper switching sequence proposed circuit generates seven levels in output voltage. Circuit diagram of proposed thirteen level multilevel inverter is shown in figure 5.

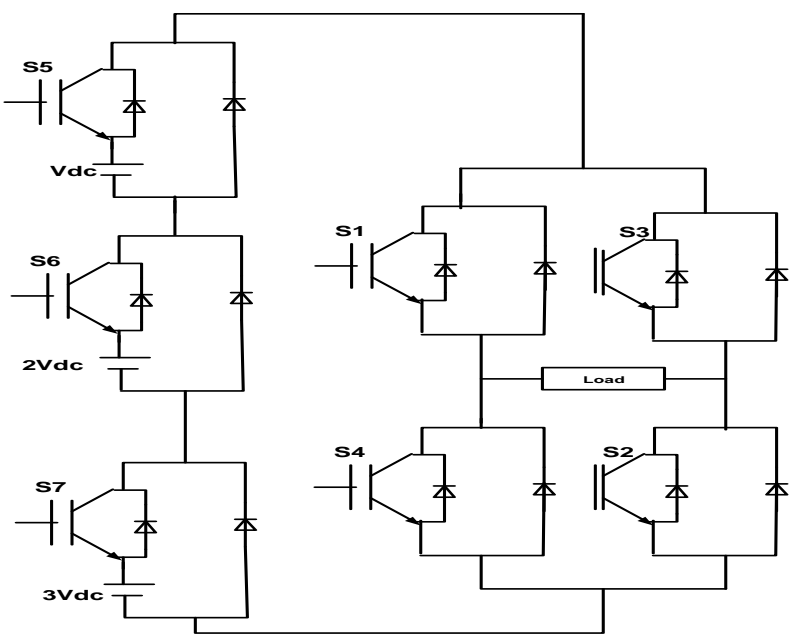

Fig5. Circuit diagram of thirteen level proposed inverter (asymmetrical configuration)
Table 2 shows the switching sequence used for creating thirteen levels for the output voltage.

Table 2: Switching Sequence for proposed thirteen level Inverter (asymmetrical configuration)

\begin{tabular}{|c|c|c|c|c|c|c|c|}
\hline Swl & Sw2 & Sw3 & Sw4 & Sw5 & Sw6 & Sw7 & $V_{\text {load }}$ \\
\hline On & On & off & off & On & On & On & $6 V_{d c}$ \\
\hline On & On & off & off & off & On & On & $5 V_{d c}$ \\
\hline On & On & off & on & On & off & On & $4 V_{d c}$ \\
\hline On & On & off & off & off & off & On & $3 V_{d c}$ \\
\hline On & On & off & off & off & On & off & $2 V_{d c}$ \\
\hline On & On & off & off & On & off & off & $V_{d c}$ \\
\hline off & On & off & On & off & off & off & 0 \\
\hline off & off & On & On & On & off & off & $-V_{d c}$ \\
\hline off & off & On & On & off & On & off & $-2 V_{d c}$ \\
\hline off & off & On & On & off & off & On & $-3 V_{d c}$ \\
\hline off & off & On & On & On & off & On & $-4 V_{d c}$ \\
\hline off & off & On & On & off & On & On & $-5 V_{d c}$ \\
\hline off & off & On & On & On & On & On & $-6 V_{d c}$ \\
\hline
\end{tabular}

The output waveform has 13 levels: $\pm 6 \mathrm{Vdc}, \pm 5 \mathrm{Vdc}, \pm 4 \mathrm{Vdc} \pm$ $3 \mathrm{Vdc}, \pm 2 \mathrm{Vdc}, \pm \mathrm{Vdc}$ and 0 . The output voltage waveform of the ideal thirteen level inverter is shown in fig6.

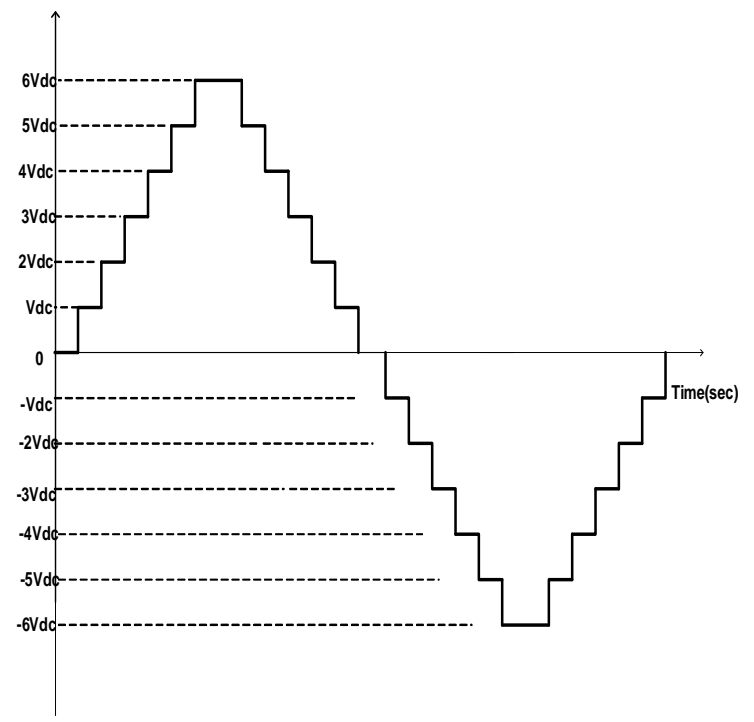

Fig6. Ideal thirteen level output voltage waveform 
The following table 3 shows the comparison between proposed MLI and conventional multilevel inverters.

Table 3: The comparison between proposed MLI and conventional multilevel inverters

\begin{tabular}{|l|l|l|}
\hline Type of Inverter & Number of switches & Number of Diodes \\
\hline $\begin{array}{l}\text { Cascaded H- } \\
\text { bridge MLI } \\
\text { (Symmetrical) }\end{array}$ & 24 & - \\
\hline $\begin{array}{l}\text { Cascaded H- } \\
\text { bridge MLI } \\
\text { (Asymmetrical) }\end{array}$ & 12 & - \\
\hline $\begin{array}{l}\text { Proposed MLI } \\
\text { (Symmetrical) }\end{array}$ & 10 & 3 \\
\hline $\begin{array}{l}\text { Proposed MLI } \\
\text { (Asymmetrical) }\end{array}$ & 7 & \\
\hline
\end{tabular}

\section{PROPOSED MULTILEVEL INVERTER FED}

\section{INDUCTION MOTOR DRIVE}

The general block diagram of the proposed system is shown in figure 7. It consists of a proposed inverter which uses less number of switches is connected to a three phase induction motor to control its speed. In this paper the inverter uses less number of switches compared conventional cascaded H-bridge inverter [9]. The proposed inverter is used control the speed and torque of the induction motor.

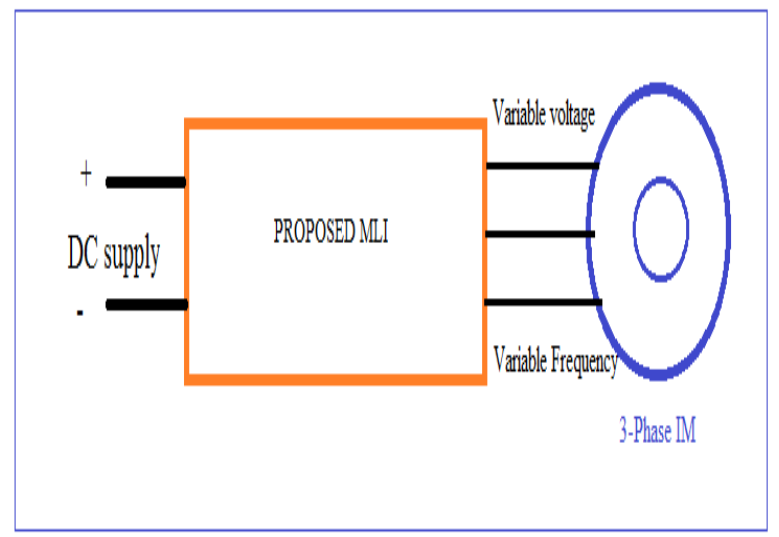

Fig7. Induction motor fed by the proposed MLI

\section{MATLAB MODELLING AND SIMULATION RESULTS}

The following figures8 and 9 shows the Matlab/Simulink diagram of proposed thirteen level MLI in symmetrical cinfiguration and its output voltage wave form.

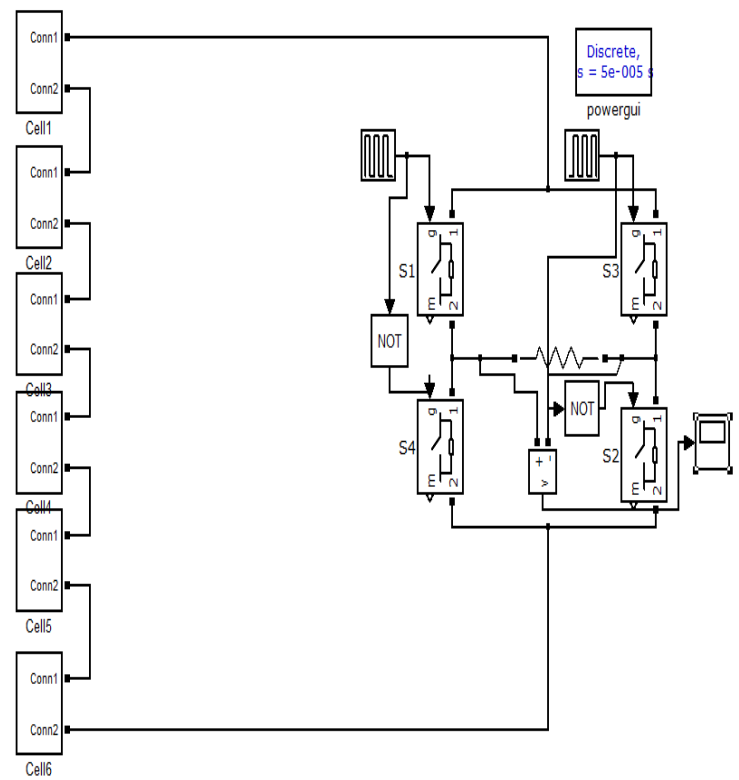

Fig8: Matlab/Simulink diagram of proposed symmetrical thirteen level MLI

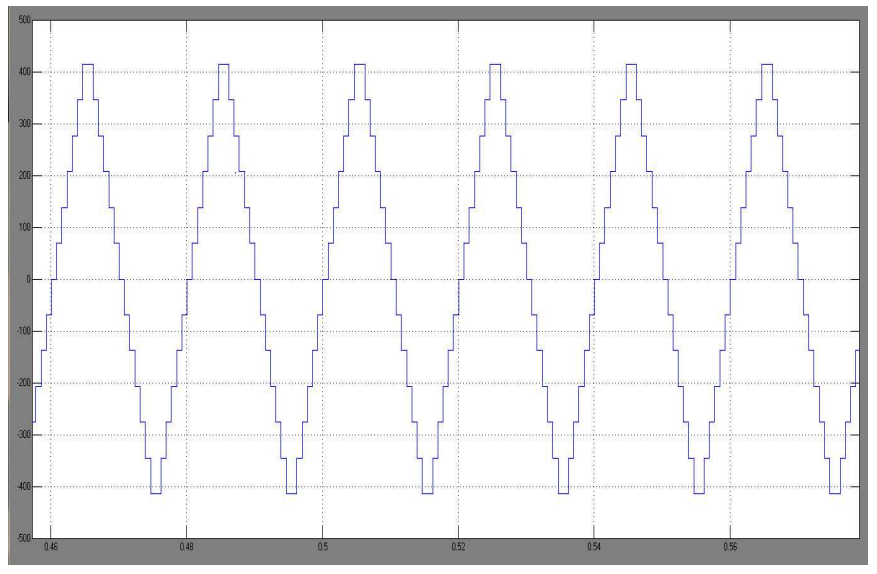

Fig9: Proposed thirteen level inverter in symmetrical configuration output voltage

From figure 9, it is observed that the output voltage of proposed MLI has thirteen levels with ten switches and six diodes. The following figure 10 shows the spectrum analysis of thirteen level output voltage. 


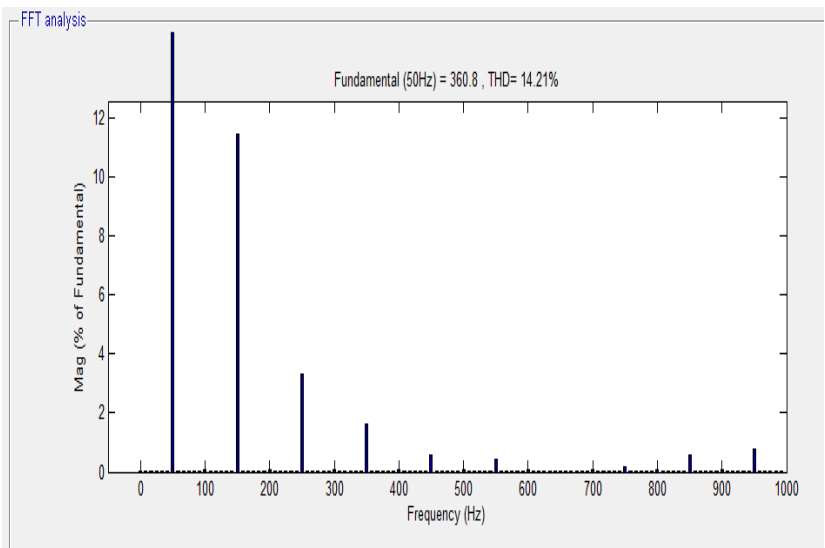

Fig10: THD of the 7-level proposed inverter

From figure 10, the THD of the proposed thirteen level MLI in symmetrical configuration is $14.21 \%$.

The following figures11 and 12 shows the Matlab/Simulink diagram of proposed thirteen level MLI in asymmetrical configuration and its output voltage wave form.

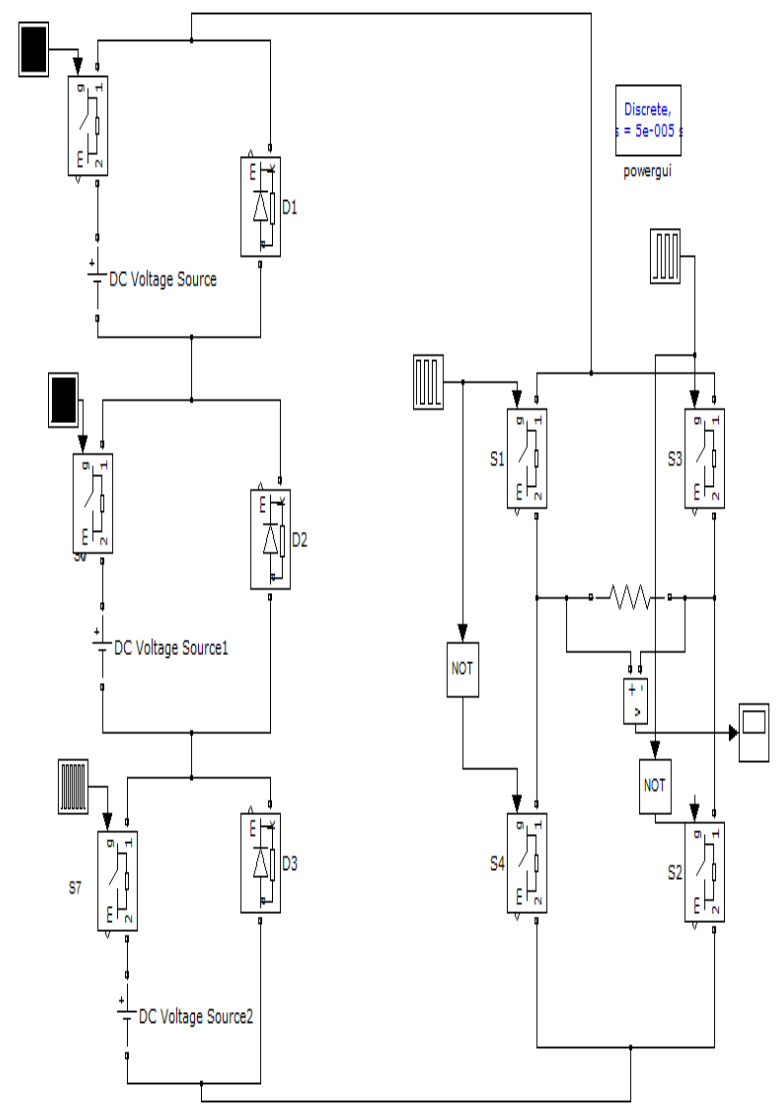

Fig11: Matlab/Simulink diagram of proposed thirteen level MLI in asymmetrical configuration

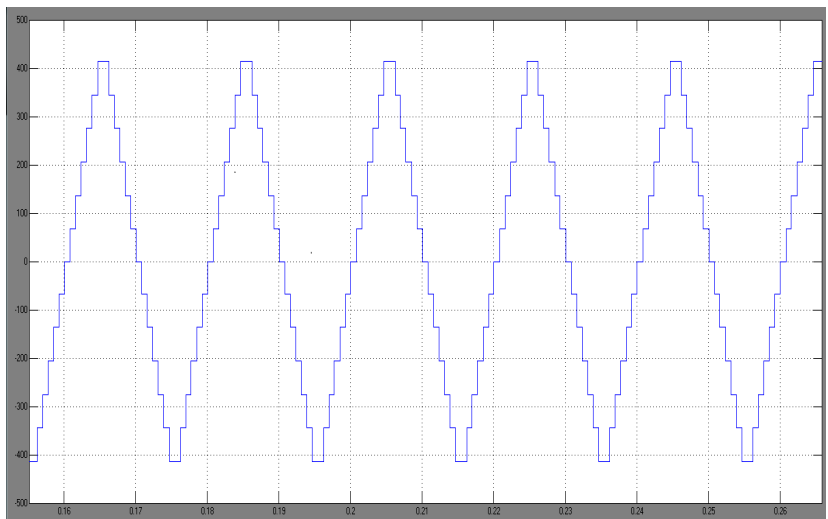

Fig12: Proposed thirteen level inverter in asymmetrical configuration output voltage

From figure 12, it is observed that the output voltage of proposed MLI in asymmetrical configuration has thirteen levels with seven switches and three diodes. The following figure 13 shows the spectrum analysis of seven level output voltage.

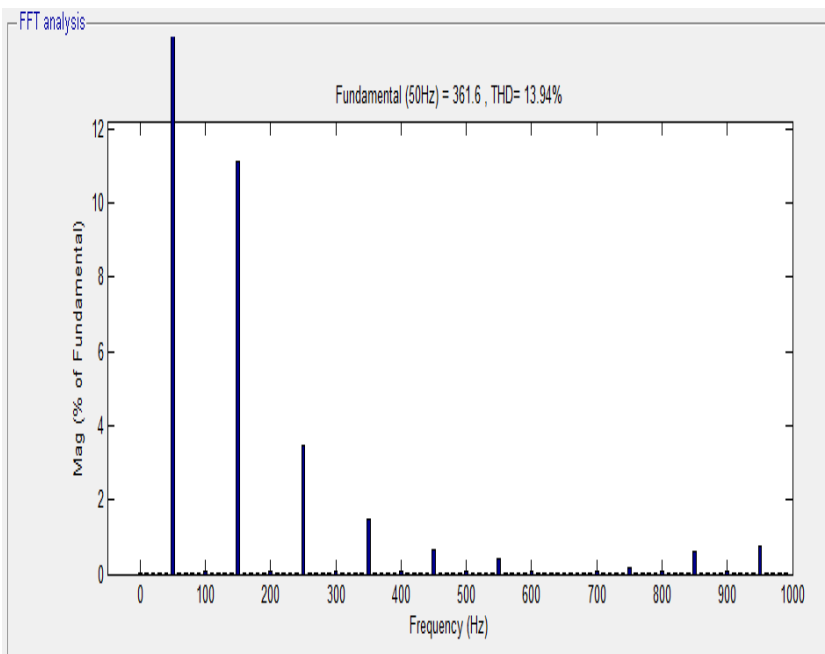

Fig13: THD of the 13-level proposed inverter

From figure 13, the THD of the proposed seven level inverter is $13.94 \%$.

Matlab/simulink diagram of induction motor drive system based on proposed inverter is shown figure 14 . 


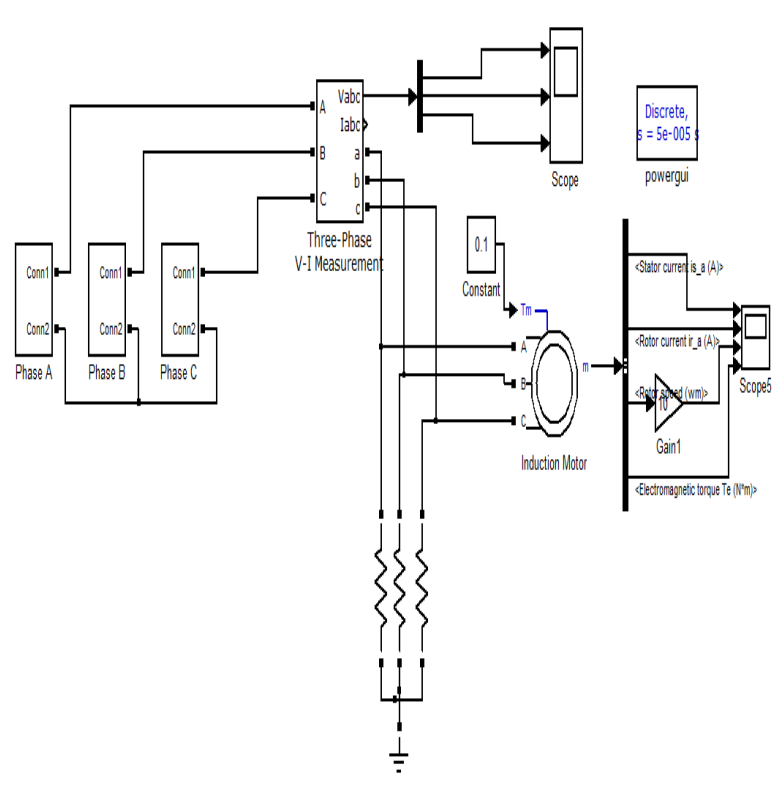

Fig 14: Matlab/Simulink diagram of proposed MLI fed induction motor drive system

The following figure 15 shows the phase voltage waveforms of the induction motor

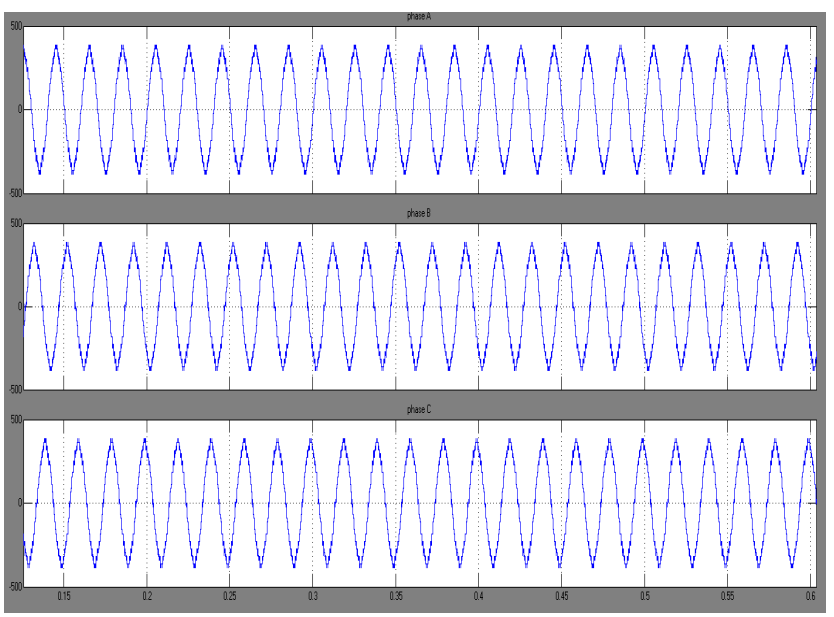

Fig15: Phase voltages of the induction motor

The following figure 16 shows stator, rotor currents, speed and electromagnetic torque of the induction motor.

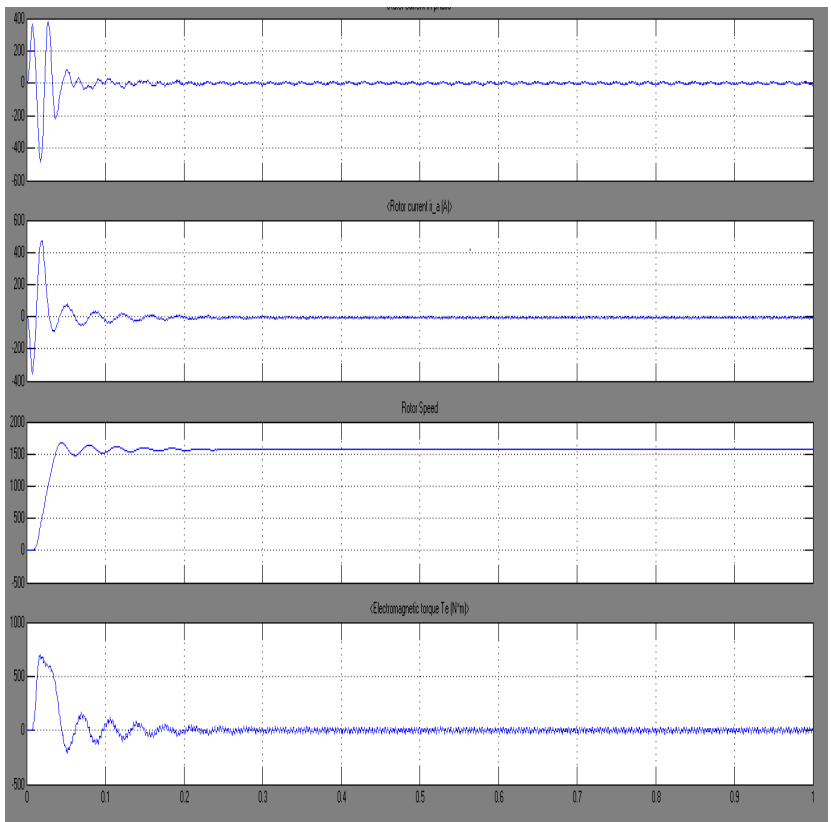

Fig 16: Stator, rotor currents, speed and electromagnetic torque of the induction motor

From above figure, the speed of the induction motor settles to constant after transient period is over.

\section{CONCLUSIONS}

This paper proposes a induction motor drive system based on new multilevel inverter with reduced number of switches. The proposed multilevel inverter uses less number of switches, hence the switching losses and cost of inverter is less compared to conventional MLIs. Increasing the number of output voltage levels reduces the lower order harmonics and the THD. It's preferred that the output voltage has no lower order harmonics because their filtering is so hard. From the results the speed and torque have less ripples.

\section{REFERENCES}

[1] "Modern power electronics and ac drives" by bimal k bose. [2] Muhammad H Rashid , "Power Electronics: circuits, Devices and Applications", Pearson Education, Third Edition, 2004.

[3] J.S. Lai and F.Z. Peng, "Multilevel Converters - A new breed of power converters," Conference Record of the IEEE-IAS Annual Meeting, 1995, pp. 2348-2356.

[4] M. Manjrekar and G. Venkataramanan, "Advanced topologies and modulation strategies for multilevel inverters," Conference Record of the IEEE-PESC, 1996, pp. 1013-1018.

[5] Mohan M. Renge and Hiralal M. Suryawanshi, "Five-Level Diode clamped Inverter to eliminate Common Mode Voltage and Reduced dv/dt in Medium voltage rating Induction Motor Drives, IEEE Transactions on Power Electronics, vol. 23, no.4, pp. 1598-1607 July 2008. 
[6] Mostafa Khazraei, Hossein Sepahvand, Keith A. Corzine, and Mehdi Ferdowsi, "Active Capacitor Voltage Balancing in Single-Phase Flying-Capacitor Multilevel Power Converters" IEEE Transactions on Industrial Electronics, VOL. 59, NO 2, FEBRUARY 2012.

[7] Xu Lie, Jon C. Clare, Patrick W. Wheeler, Lee Empringham, and Li Yongdong, "Capacitor Clamped Multilevel Matrix Converter Space Vector Modulation" IEEE Transactions on industrial electronics, VOL. 59, NO. 1, JANUARY 2012.

[8] Fernanda Carnielutti, Humberto Pinheiro, and Cassiano Rech, "Generalized Carrier-Based Modulation Strategy for Cascaded Multilevel Converters Operating Under Fault Conditions" IEEE Transactions on Industrial Electronics, VOL. 59, NO. 2, FEBRUARY 2012.

[9] J. Rodriguez, J.-S. Lai, and F. Z. Peng, "Multilevel inverters: a survey of topologies, controls, and applications," IEEE Trans. Ind. Electron., vol. 49, pp. 724 -738, 2002.

\section{BIOGRAPHIES}

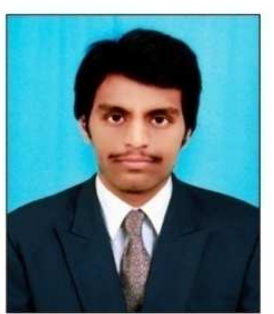

V S Prasadarao K Received the B.TECH degree in Electrical and Electronics from Lakireddy Balireddy College of engineering, Mylavaram, Krishna (DT), A.P, India, in 2011 and MTECH in power Electronics and Electrical drives from Gudlavalleru engineering college, Gudlavalleru, Krishna (DT), A.P, India. Currently he is working as Research Engineer in Naresh Engineering Coaching (NEC) Institute, Vijayawada, Krishna (DT), A.P, India. His interested areas are in the field of renewable energies, power converters, and electrical drives.

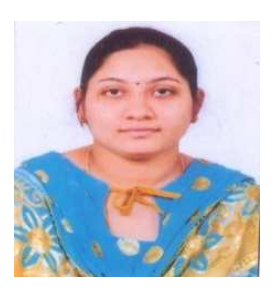

Gandham Tabita Received the B.TECH degree in Electrical and Electronics Engineering from Bapatla Engineering College, Bapatla, Guntur (DT), A.P, India, in 2005. Currently she is pursuing M.TECH Gudlavalleru engineering college, Gudlavalleru, Krishna (DT), A.P, India. Her research interests include Power Converters, Electrical Drives, and machines. 